\title{
Role of IGFBP1 in the senescence of vascular endothelial cells and severity of aging-related coronary atherosclerosis
}

\author{
XIAOJING WU ${ }^{1}$, WEI ZHENG ${ }^{2}$, PENG JIN $^{2}$, JUNHAO $\mathrm{HU}^{3}$ and QI ZHOU ${ }^{3}$ \\ ${ }^{1}$ Cardiovascular Department of Shenzhen University General Hospital and Shenzhen University Clinical \\ Medical Academy, Shenzhen, Guangdong 518060; ${ }^{2}$ Cardiovascular Department of Xinqiao Hospital, \\ Chongqing 400037; ${ }^{3}$ Cardiovascular Department of The Second Affiliated Hospital of \\ Chongqing Medical University, Chongqing 400010, P.R. China
}

Received April 19, 2019; Accepted August 22, 2019

DOI: $10.3892 /$ ijmm.2019.4338

\begin{abstract}
The senescence of vascular endothelial cells (ECs) plays a critical role in aging-related cardiovascular diseases. We previously reported the causal relation of Jagged1 in ECs and the thickening of the arterial wall in aging mice. The aim of the present study was to further investigate the correlation between insulin-like growth factor-binding protein 1 (IGFBP1), one of the secretory proteins regulated by Jagged1, and the severity of coronary atherosclerosis and patient age, as well as its effect on EC senescence. First, microarray analysis was performed to screen the differentially expressed genes regulated by Jagged1 in human coronary arterial ECs (HCAECs). Inhibition of the Jagged1 expression using a small interfering RNA knockdown method in HCAECs led to the upregulation of 17 and the downregulation of 78 genes by $>3$-fold, and IGFBP1 was confirmed to be a secretory protein expressed by HCAECs and regulated by Jagged1. Subsequently, in 112 consecutively enrolled patients with acute chest pain who underwent coronary angiography, the circulating level of IGFBP1 was found to be positively correlated with age $(r=0.512, P<0.001)$ and Synergy between PCI with TAXUS and Cardiac Surgery (SYNTAX) score $(r=0.409$, $\mathrm{P}<0.001)$. Among age-comparable patients, the circulating IGFBP1 level was found to be increased in patients with higher SYNTAX scores. In cultured HCAECs, IGFBP1 was shown to protect ECs against passage- or $\mathrm{H}_{2} \mathrm{O}_{2}$-induced senescence, and
\end{abstract}

Correspondence to: Professor Xiaojing $\mathrm{Wu}$, Cardiovascular Department of Shenzhen University General Hospital and Shenzhen University Clinical Medical Academy, 1098 Xueyuan Street, Nanshan, Shenzhen, Guangdong 518060, P.R. China

E-mail: xiaojingwu1992@163.com

Dr Qi Zhou, Cardiovascular Department of The Second Affiliated Hospital of Chongqing Medical University, 74 Linjiang Road Yuzhong, Chongqing 400010, P.R. China

E-mail: drzhouqi@126.com

Key words: coronary artery disease, cell senescence, endothelial cells, aging these protective effects of IGFBP1 may be partially reversed by LY294002, a known Akt signaling inhibitor. Therefore, the results of the present study suggested that, as a downstream protein of Jagged1, IGFBP1 was correlated with the severity of coronary atherosclerosis in aging patients, and the increase of circulating IGFBP1 levels with aging may be an adaptive response to counter HCAEC senescence through Akt signaling.

\section{Introduction}

As an independent risk factor, aging contributes to cardiovascular morbidity and mortality $(1,2)$. The characteristic changes of vascular aging include thickening and stiffness of the vessel wall, which are considered to be largely due to the senescence of vascular endothelial cells (ECs) $(3,4)$. Senescent cells usually exhibit a diminished proliferative potential; in particular, the senescent state of cells is often accompanied with the secretion of proteins that may promote the senescent phenotype and adversely affect local tissue environment $(5,6)$. It has demonstrated that vascular ECs are crucial for maintaining vascular homeostasis (7). ECs may affect adjacent smooth muscle cells, and exert dominant regulatory effects on embryonic vascularization and postnatal vascular remodeling $(8,9)$. Thus, EC senescence is a critical factor in aging-related vascular disorders.

Notch signaling has attracted increasing attention due to its key role in the regulation of events ranging from vascular formation to vascular aging $(10,11)$. During the development of embryonic vasculature, the expression of Notch signaling molecules, including Jagged1 and Notch1, determines the arterial identity of the vessel (11). In postnatal artery remodeling, members of the Jagged/Notch gene families are expressed in injured arteries, which regulate cell phenotype via alterations in cell-matrix and cell-cell interactions (12). Our previous study demonstrated that conditional knockdown of Jagged1 expression in EC caused thickening of the vessel wall in mice (8). However, the underlying mechanism remains largely unknown.

It has been established that human atherogenesis is initiated during fetal development, although and the progression into atherosclerosis usually takes decades. With aging, the 
incidence and severity of coronary artery atherosclerosis increases $(1,13)$. To further elucidate the role of Jagged1 in aging-related vascular disorders, the differentially expressed secretory protein genes regulated by Jagged1 in human coronary arterial ECs (HCAECs) were screened. One of the regulated secretory proteins, insulin-like growth factor-binding protein 1 (IGFBP1), was identified as a factor of interest. IGFBP1 is a $30-\mathrm{kDa}$ protein that has been implicated in metabolic homeostasis. Higher IGFBP1 levels were previously found to be associated with lower metabolic risk (14). Its impact on the progress of macro-vascular diseases in diabetes attracted much attention (15); however, its role in aging-related atherosclerosis in non-diabetes remains largely unknown. The aim of the present study was to determine whether there is a correlation between IGFBP1 with aging and the severity of coronary artery diseases, and whether IGFBP1 exerts an anti-senescence effect on cultured HCAECs.

\section{Materials and methods}

Patient enrollment and study design. A total of 112 patients aged $>18$ years with clinically diagnosed acute coronary syndrome according to current guidelines were consecutively enrolled at Xinqiao Hospital between July 2014 and July 2016. Major exclusion criteria included the following: Diabetes or impaired glucose tolerance, obesity, hypertension, dyslipidemia, infection, and impaired liver or renal function. Patients with previous percutaneous coronary intervention or coronary artery bypass grafting were also excluded. Of the 112 enrolled subjects, the age of the patients ranged between 26 and 83 years old, and 66 cases $(58.93 \%)$ were male. Patients aged $\leq 65$ years old were included in the young group $(n=50$, mean age, $51.70 \pm 6.65$ years) and patients aged $>65$ years old were included in the old group ( $\mathrm{n}=62$, mean age, $69.11 \pm 5.69$ years). All the patients underwent coronary angiography (CAG) according to standard techniques. Fasting peripheral venous blood was collected from all patients for the IGFBP1 assay. This study was approved by the Institutional Ethics Committee of Xinqiao Hospital (approval no. 2014044), and the investigation conformed to the principles outlined in the Declaration of Helsinki. Written informed consent was obtained from all enrolled subjects.

Assessment of the severity of coronary arterial lesions. The severity of coronary artery stenosis was assessed by at least two experienced interventional cardiologists. Critical coronary artery disease (CAD) was defined as a segment with $\geq 50 \%$ stenosis in any major epicardial artery or any important branch of a major epicardial coronary artery. The severity of CAD was assessed by the number of diseased vessels and the value of the Synergy between PCI with TAXUS and Cardiac Surgery (SYNTAX) score. The SYNTAX score was calculated using the online updated calculator version (http://www. syntaxscore.com), and each coronary lesion with a stenosis diameter of $\geq 50 \%$ in vessels $\geq 1.5 \mathrm{~mm}$ in diameter was scored. Patients were categorized as mild (scores $\leq 22$ ) vs. moderate and severe stenosis (scores $\geq 23$ ).

Cell culture, transfection of small interfering RNA (siRNA) and microarray analysis. HCAEC cultures were obtained from PromoCell GmbH. HCAECs were cultured in endothelial growth medium (EGM, Lonza Group, Ltd.) with $10 \%$ fetal bovine serum (FBS; Gibco; Thermo Fisher Scientific, Inc.) and incubated at $37^{\circ} \mathrm{C}$ in a humidified atmosphere with $5 \% \mathrm{CO}_{2}$, according to manufacturer's protocol. HCAEC of passages 5-7 were transfected at 50\% confluence with $20 \mathrm{nM}$ siRNA of Jagged1 (siJagged1, Shanghai GenePharma Co., Ltd.) or with $20 \mathrm{nM}$ control siRNA (siControl, Shanghai GenePharma Co., Ltd.; Table SI) in Opti-MEM I Reduced Serum Medium (Gibco; Thermo Fisher Scientific, Inc.), using Lipofectamine ${ }^{\circledR} 2000$ (Invitrogen; Thermo Fisher Scientific, Inc.). After $4 \mathrm{~h}$ of transfection, the medium was replaced with fresh complete media. The cells were maintained for $48 \mathrm{~h}$ before total RNA was extracted and analyzed with Human Whole Genome OneArray V6.2 (HOA6.2; Phalanx Biotech Group) by BGI Sequencing Co., Ltd. as previously reported (16) HOA6.2 contains 32,679 DNA oligonucleotide probes, and each probe is a 60 -mer designed in the sense direction. Among the probes, 31,741 correspond to the annotated genes in RefSeq v51and Ensembl r65 database. Detailed description of microarray procedures and whole genome gene and probe lists are available from http://www.phalanxbiotech. com/tech_support/general.php.

Cell senescence and proliferation assay. As previously reported, in vitro endothelial culture may serve as a marker for in vivo aging (17). Passaging may induce the senescence of cultured ECs (18). Approximately 3 days were required for the early passages of ECs ( $<6$ passages) to reach confluence. However, the majority of the cells became non-mitotic after $>10$ passages (18). In our culture system, HCAECs of passage 5 (P5) were used as young and of passage 20 (P20) were used as old cells for comparison. Briefly, HCAECs were inoculated in 6-well plates (Corning, Inc.) in EGM with $10 \%$ FBS and incubated at $37^{\circ} \mathrm{C}$ in a humidified atmosphere with $5 \% \mathrm{CO}_{2}$. After $24 \mathrm{~h}$, the medium was changed with fresh serum-free medium and cultured at $37^{\circ} \mathrm{C}$ for another $24 \mathrm{~h}$. HCAECs were then treated with $\mathrm{H}_{2} \mathrm{O}_{2}(0,100 \mu \mathrm{mol} / \mathrm{l})$ for $4 \mathrm{~h}$, followed by treatment with IGFBP1 $(0,5,50$ and $100 \mathrm{ng} / \mathrm{ml}$; RayBiotech) or IGFBP1 plus LY294002 (10 $\mu \mathrm{mol} / 1$, Sigma Aldrich; Merck $\mathrm{KGaA}$ ) in EGM (Lonza Group, Ltd.) with 0.5\% FBS (Gibco; Thermo Fisher Scientific, Inc.) at $37^{\circ} \mathrm{C}$ for $48 \mathrm{~h}$. Subsequently, the HCAECs were harvested for cell senescence and proliferation assays. The senescence-associated $\beta$-gal was determined with a corresponding kit according to the manufacturer's protocol (Sigma-Aldrich; Merck KGaA). The proliferation assays were performed using a Cell Counting Kit-8 (CCK-8; Dojindo Molecular Technologies, Inc.) and tritiated thymidine $\left({ }^{3} \mathrm{H}-\mathrm{TdR}\right)$ incorporation (Shanghai Nuclear Institute) according to the manufacturer's protocols, as previously described (9).

IGFBPI assay. The levels of circulating IGFBP1 in the enrolled subjects, as well as in the culture supernatant of HCAECs, were measured using ELISA. Briefly, $\sim 3 \mathrm{ml}$ of blood sample was collected in a vacuum tube from each patient after an overnight fast. The blood sample was allowed to clot for 30-60 min at room temperature, and then each clotted sample was centrifuged at $1,500 \mathrm{xg}$ for $10 \mathrm{~min}$ at $4^{\circ} \mathrm{C}$. The serum samples were then frozen at $-70^{\circ} \mathrm{C}$ until the concentration of IGFBP1 was measured. In HCAEC culture, following transfecting 

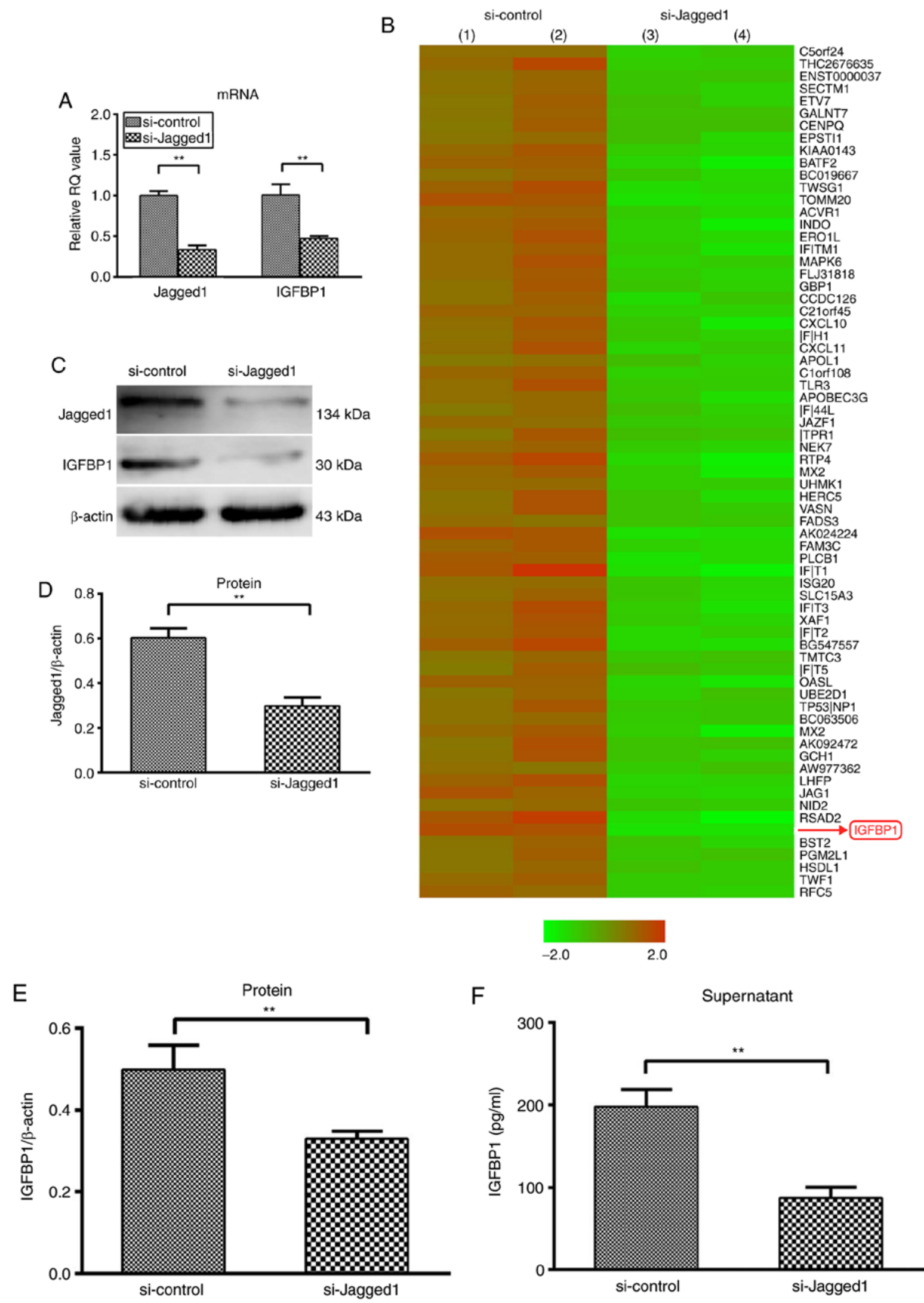

Figure 1. Knockdown of Jagged1 decreased the expression of IGFBP1 in HCAEC and in the supernatant. (A) Reverse transcription-quantitative polymerase chain reaction analysis of the relative mRNA expression of Jagged1 and IGFBP1 in HCAEC $48 \mathrm{~h}$ after transfection with siJagged1 or siControl. One of two independent experiments, each with three biological replicates, is shown. (B) Microarray screening of genes regulated by Jagged1 in HCAECs $48 \mathrm{~h}$ after transfection with siJagged1 or siControl. Red represented upregulation and green indicated downregulation. Representative images of two independent experiments, each with two biological replicates. (C) Representative image of western blot detection of Jagged1 and IGFBP1 protein in HCAEC $48 \mathrm{~h}$ after transfection with siJagged1 or siControl. Quantification of western blot band density of (D) Jagged1 and (E) IGFBP1. One of two independent experiments, each with three biological replicates, is shown. (F) Quantification of IGFBP1 protein by ELISA in the culture supernatant of HCAECs $48 \mathrm{~h}$ after transfection with siJagged1 or siControl. One of two independent experiments, each with three biological replicates, is shown. For A, D, E and F, data are presented as the mean \pm standard deviation; ${ }^{* *} \mathrm{P}<0.01$. IGFBP1, insulin-like growth factor-binding protein 1; HCAECs, human coronary arterial endothelial cells; si, small interfering RNA. 
with Jagged1 siRNA or siControl, the ECs were cultured with serum-free medium for $48 \mathrm{~h}$ and the supernatants were collected and stored as described above. The levels of IGFBP1 (sensitivity: $5 \mathrm{pg} / \mathrm{ml}$, cat. no. ELH-IGFBP1, RayBiotech) were then assayed according to the manufacturer's instructions. Data are expressed as units of $\mathrm{ng} / \mathrm{ml}$.

Reverse transcription-quantitative polymerase chain reaction $(R T-q P C R)$ analysis. Total RNA was extracted from cultured HCAECs with an RNAiso kit according to the manufacturer's instruction (Takara Bio, Inc.). RT was performed using the PrimeScript ${ }^{\circledR}$ RT reagent kit (Takara Bio, Inc.) and qPCR was performed using the SYBR ${ }^{\circledR}$ Premix Ex Taq ${ }^{\mathrm{TM}}$ (Takara Bio, Inc.) in a 7500 Fast Real Time PCR System (Applied Biosystems; Thermo Fisher Scientific, Inc.) according to the manufacturers' protocols, respectively. The reaction condition for qPCR included two stages. Stage 1, Initial denaturation: $95^{\circ} \mathrm{C}$ for $30 \mathrm{sec}$; stage $2,95^{\circ} \mathrm{C}$ for $5 \mathrm{sec}$ and $60^{\circ} \mathrm{C}$ for $34 \mathrm{sec}$ with 40 cycles. The specific primers of IGFBP1, Jagged 1 and GAPDH were designed by Fulengene (Table SII). The $2^{-\Delta \Delta \mathrm{Cq}}$ method was used to determine the relative mRNA expression of target genes after normalization to housekeeping gene GAPDH as previously reported (19).

Western blot analysis. Whole-cell lysates were prepared from cultured HCAECs with radioimmunoprecipitation assay buffer (Santa Cruz Biotechnology, Inc.), and the lysates were then separated via 10\% SDS-PAGE, transferred to polyvinylidene fluoride membranes, and probed with antibodies: Rabbit anti-Jagged1 (1:1,000; cat. no. ab109536, Abcam), rabbit anti-IGFBP1 (1:1,000; cat. no. ab181141; Abcam), rabbit anti-Akt (1:1,000; cat. no. 4691, Cell Signaling Technology, Inc.), rabbit anti phosphorylated (p)-Akt (1:1,000; cat. no. 4060, Cell Signaling Technology, Inc.) and rabbit anti- $\beta$ actin $(1: 1,000$; cat. no. ab8227; Abcam) by standard procedures.

Statistical analysis. Statistical analysis was performed using SPSS software, version 20.0 (IBM Corp.). Continuous variables were summarized as mean \pm standard deviation or medians and interquartile ranges, and all categorical variables were expressed as proportions. Two groups were compared with independent samples $t$ test. Datasets containing three or more groups were first analyzed by one-way ANOVA, and significance between any two groups was further analyzed by post hoc test. For the post hoc tests, the least significant difference test was used for comparing three groups and a Bonferroni test was used for comparing four groups. If all comparisons were compared with the control group, the Dunnett's post hoc test was used. Correlations between IGFBP1 level and severity of coronary arterial lesions were assessed by calculating the Spearman's correlation coefficients. $\mathrm{P}<0.05$ was considered to indicate a statistically significant difference.

\section{Results}

IGFBP1 is a secretory protein regulated by Jagged1 in HCAECs. siRNA-mediated knockdown demonstrated that inhibition of Jagged1 expression (Fig. 1A) in HCAECs led to the upregulation of 17 and the downregulation of 78 genes by
Table I. Basic data of enrolled subjects.

Variables

Total subjects $(\mathrm{n}=112)$

Age, years

$61.34 \pm 10.63$

Male sex, n (\%)

$66(58.93)$

BMI, kg/m²

$23.78 \pm 2.79$

Cigarette smoking, n (\%)

48 (42.86)

Blood pressure, n (\%)

$54(48.21)$

Systolic, $\mathrm{mmHg}$

$132.56 \pm 18.21$

Diastolic, $\mathrm{mmHg}$

$76.59 \pm 11.34$

Lipids

35 (31.25)

TC, mmol/l

$4.19 \pm 0.98$

TG, mmol/1

ApoB, g/l

1.27 (0.96-1.48)

$0.77 \pm 0.21$

$1.10 \pm 0.28$

$2.55 \pm 0.71$

LDL, mmol/l

$95(84.82)$

$75(66.96)$

$76(67.86)$

22 (19.64)

95 (84.82)

14 (12.50)

67 (59.82)

$41(36.61)$

$26(23.21)$

$4.72 \pm 0.60$

28.95 (10.23-64.23)

BNP, pg/ml

$11.85(7.11-24.67)$

BMI, body mass index; TC, total cholesterol; TG, total triglyceride; ApoB, apolipoprotein B; HDL, high-density lipoprotein; LDL, lowdensity lipoprotein; ACEIs, angiotensin-converting enzyme inhibitors; $\mathrm{ARBs}$, angiotensin receptor blockers; BNP, brain natriuretic peptide; IGFBP1, insulin-like growth factor-binding protein-1.

$>3$-fold (Fig. 1B). Among the downregulated genes, IGFBP1 encodes a secretory protein and has been reported to be associated with cardiovascular disease risk and formation of vascular lesions $(20,21)$. The downregulation of IGFBP1 mRNA was further confirmed by the reduced protein expression of IGFBP 1 , both in HCAECs $(0.498 \pm 0.060$ vs. $0.330 \pm 0.019$; $\mathrm{P}<0.01)$ and in the culture supernatant $(197.93 \pm 20.81 \mathrm{pg} / \mathrm{ml}$ vs. $86.93 \pm 13.35$ pg/ml; P<0.01) (Fig. 1C-F).

Circulating IGFBPI levels are positively correlated with patient age. To elucidate the role of IGFBP1 in aging-related coronary atherosclerosis, the association of circulating IGFBP1 levels with age was first examined. The basic clinical data of the enrolled subjects are shown in Table I. Of the 112 enrolled subjects, the circulating level of IGFBP1 in the old group [median, $15.41 \mathrm{ng} / \mathrm{ml}$; interquartile range (IQR), 9.64-30.54 ng/ml] was higher compared with that in the young group (median, $10.30 \mathrm{ng} / \mathrm{ml}$; IQR, 5.14-14.25 ng/ml) (Table II; Fig. 2A). The detected IGFBP1 level was positively correlated 
Table II. Basic clinical data of young and old patients.

\begin{tabular}{|c|c|c|c|}
\hline Variables & Young group $(\leq 65$ years $)(n=50)$ & Old group ( $>65$ years $)(n=62)$ & P-value \\
\hline Age, years & $51.70 \pm 6.65$ & $69.11 \pm 5.69$ & $<0.001$ \\
\hline Male sex, n (\%) & $28(56.00)$ & $38(61.29)$ & 0.572 \\
\hline BMI, $\mathrm{kg} / \mathrm{m}^{2}$ & $24.11 \pm 2.67$ & $23.51 \pm 2.89$ & 0.257 \\
\hline Cigarette smoking, n (\%) & $22(44.00)$ & $26(41.94)$ & 0.826 \\
\hline Blood pressure, n (\%) & $22(44.00)$ & $32(51.61)$ & 0.423 \\
\hline $\mathrm{SBP}, \mathrm{mmHg}$ & $131.58 \pm 18.13$ & $133.35 \pm 18.39$ & 0.610 \\
\hline $\mathrm{DBP}, \mathrm{mmHg}$ & $78.70 \pm 11.90$ & $74.89 \pm 10.67$ & 0.077 \\
\hline Lipids & $19(38.00)$ & $16(25.81)$ & 0.166 \\
\hline $\mathrm{TC}, \mathrm{mmol} / \mathrm{l}$ & $4.37 \pm 1.06$ & $4.04 \pm 0.88$ & 0.069 \\
\hline $\mathrm{TG}, \mathrm{mmol} / \mathrm{l}$ & $1.42(1.04-1.97)$ & $1.15(0.91-1.49)$ & 0.022 \\
\hline ApoB, g/l & $0.81 \pm 0.24$ & $0.73 \pm 0.18$ & 0.039 \\
\hline HDL, mmol/l & $1.07 \pm 0.27$ & $1.13 \pm 0.29$ & 0.306 \\
\hline LDL, mmol/1 & $2.73 \pm 0.78$ & $2.40 \pm 0.63$ & 0.014 \\
\hline \multicolumn{4}{|l|}{ Medications } \\
\hline Antiplatelets, n (\%) & $42(84.00)$ & $53(85.48)$ & 0.828 \\
\hline ACEIs or ARBs, n (\%) & $32(64.00)$ & $43(69.35)$ & 0.549 \\
\hline$\beta$-blockers, n (\%) & $35(70.00)$ & $41(66.13)$ & 0.663 \\
\hline $\mathrm{CCB}, \mathrm{n}(\%)$ & $9(18.00)$ & $13(20.97)$ & 0.694 \\
\hline Statins, n (\%) & $43(86.00)$ & $52(83.87)$ & 0.755 \\
\hline Diuretics, n (\%) & $4(8.00)$ & $10(16.13)$ & 0.196 \\
\hline Coronary artery disease, $\mathrm{n}(\%)$ & $28(56.00)$ & $39(62.90)$ & 0.459 \\
\hline Multi-vessel lesions, n (\%) & $13(26.00)$ & $28(45.16)$ & 0.036 \\
\hline Single-vessel lesions, n (\%) & $15(30.00)$ & $11(17.74)$ & 0.127 \\
\hline Glucose, $\mathrm{mmol} / \mathrm{l}$ & $4.68 \pm 0.56$ & $4.75 \pm 0.64$ & 0.599 \\
\hline $\mathrm{BNP}, \mathrm{pg} / \mathrm{ml}$ & $19.05(5.65-43.15)$ & $42.05(13.95-79.00)$ & 0.006 \\
\hline IGFBP1 (ng/ml) & $10.30(5.14-14.25)$ & $15.41(9.64-30.54)$ & 0.001 \\
\hline
\end{tabular}

BMI, body mass index; SBP, systolic blood pressure; DBP, diastolic blood pressure; TC, total cholesterol; TG, total triglyceride; ApoB, apolipoprotein B; HDL, high-density lipoprotein; LDL, low-density lipoprotein; ACEIs, angiotensin-converting enzyme inhibitors; ARBs, angiotensin receptor blockers; CCB, calcium channel blockers; BNP, brain natriuretic peptide; IGFBP1, insulin-like growth factor-binding protein-1.

with the age of all enrolled subjects $(r=0.505, \mathrm{P}<0.001)$ (Fig. 2B).

Association between IGFBPI level and aging-related coronary atherosclerosis. We then investigated the associations between the severity of coronary arterial lesions and circulating IGFBP1 levels in each age group. Of the 112 enrolled subjects, $67(59.82 \%)$ were diagnosed by CAG with critical CAD and 45 cases $(40.18 \%)$ with non-critical CAD (Table I). Among patients with critical CAD, 28 cases $(41.79 \%$, data not shown) were in the young group and 39 cases $(58.21 \%$, data not shown) were in the old group (Fig. 3A, Table II). The incidence of multi-vessel disease and SYNTAX score were significantly higher in old critical CAD patients compared with those in young critical CAD patients, suggesting a link between aging and the severity of coronary arterial lesions (Fig. 3A and B).

In addition, among the 67 patients with critical CAD, the circulating level of IGFBP1 was significantly higher in patients with multi-vessel lesions $(26.08 \mathrm{ng} / \mathrm{ml}$; IQR, 11.63-42.26 ng/ml) compared with those with single-vessel lesions (11.26 ng/ml; IQR, 7.01-16.13 ng/ml, P<0.01), and IGFBP1 was positively correlated with SYNTAX score (Fig. 3C and D). Consistently, the circulating level of IGFBP1 was positively correlated with age in critical CAD patients. In particular, among age-comparable patients with critical CAD, the circulating level of IGFBP1 was increased in patients with higher SYNTAX scores (Fig. 3E), suggesting a potential link between circulating IGFBP1 level and aging-related severity of coronary atherosclerosis.

IGFBPI protects HCAEC against senescence. To explore the role of increased IGFBP1 level in aging-related coronary arterial lesions, we further examined the effects of IGFBP1 on the senescence of HCAECs. P5 HCAECs were used as young cells and P20 as old cells for comparison. We found that very few $\beta$-gal-positive cells were present in the P5 EC cultures, while a number of strongly $\beta$-gal-positive cells was found in the P20 cultures. The ratio of $\beta$-gal-positive cells was significantly higher among P20 cells compared with

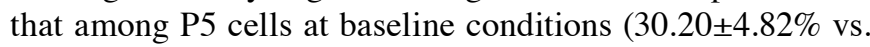


A

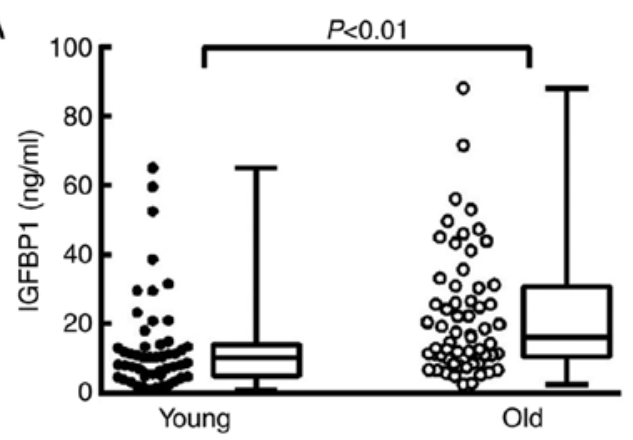

B

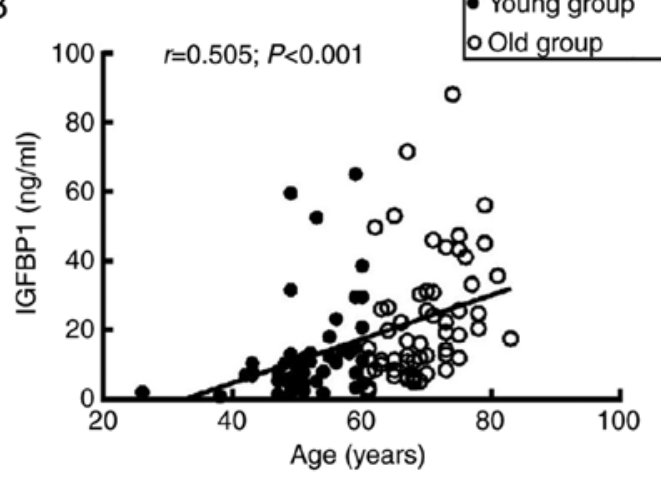

Figure 2. Correlation of circulating IGFBP1 level with age. (A) IGFBP1 levels in the 112 enrolled subjects were assessed via ELISA. A total of 50 cases were in the young group, with a mean age of 51.70 years, and 62 cases were in the old group, with a mean age of 69.11 years. The circulating level of IGFBP1 was significantly higher in the old group compared with that in the young group. (B) Correlation of age and circulating IGFBP1 level. The level of IGFBP1 was positively correlated with age in all the enrolled patients. For IGFBP1, each sample was assayed in duplicate. Data are expressed as medians and interquartile ranges. $\mathrm{P}<0.05$ was considered statistically significant. IGFBP1, insulin-like growth factor-binding protein 1.

A

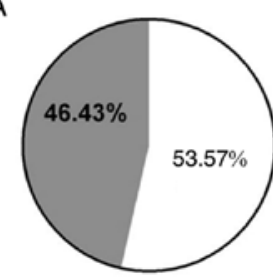

Young $(\mathrm{n}=28)$

$\square$ Single-vessel lesion

C

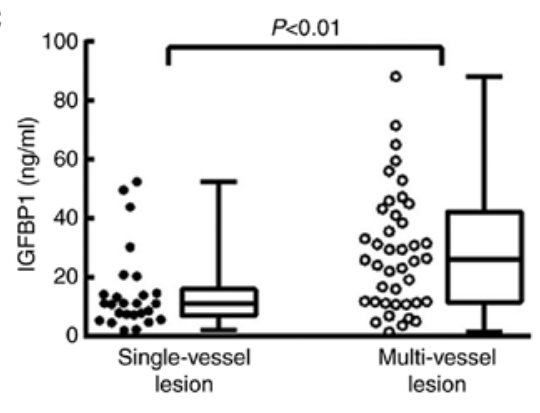

B

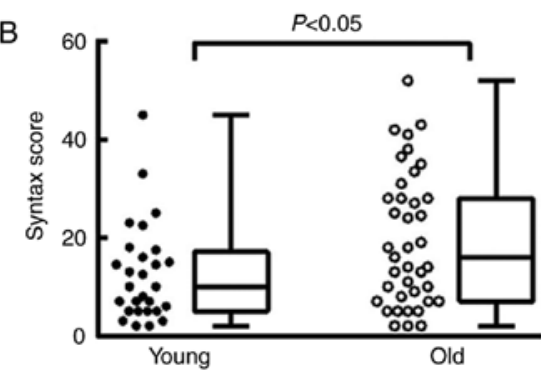

D

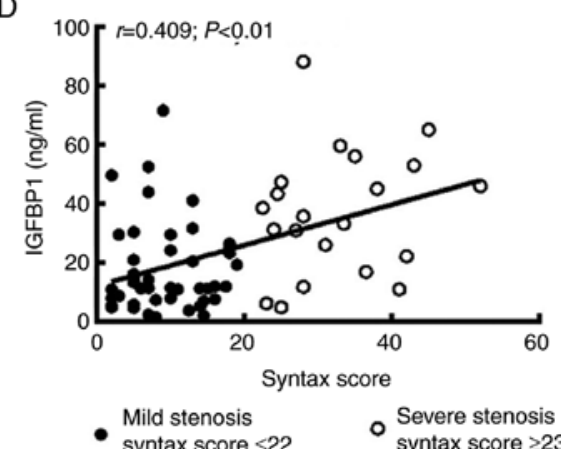

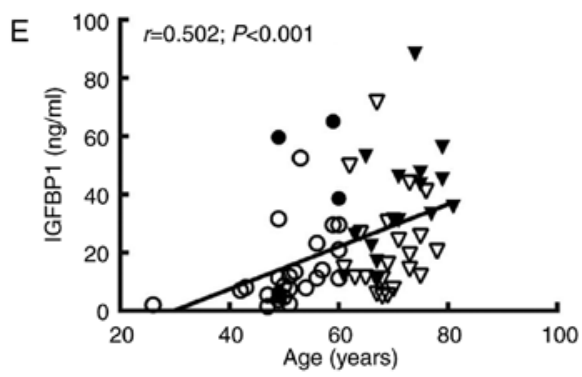

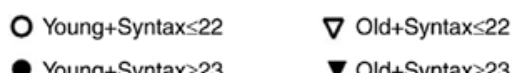

Figure 3. Correlation between circulating IGFBP1 levels with age and coronary lesion severity in critical CAD patients. (A) Incidence of multi-vessel and single-vessel disease in critical CAD patients. Of the 67 critical CAD patients, 28 were in the young group and 39 were in the old group. The incidence of multi-vessel disease was higher among the old critical CAD patients compared with that among the young critical CAD patients. (B) SYNTAX scores in young vs. old CAD patients. (C) IGFBP1 levels in the single-vessel vs. multi-vessel CAD patients. (D) Correlation of IGFBP1 level and SYNTAX scores in CAD patients with mild vs. severe stenosis. (E) IGFBP1 levels, age and severity of coronary lesions. The circulating levels of IGFBP1 was positively correlated with age in critical CAD patients, and its level was higher in patients with severe stenosis vs. age-comparable patients with less severe lesions. For the quantification of IGFBP1, each sample was assayed in duplicate. Continuous variables were summarized as medians and interquartile ranges, and categorical variables were expressed as proportions. $\mathrm{P}<0.05$ was considered statistically significant. IGFBP1, insulin-like growth factor-binding protein 1 ; CAD, coronary artery disease; SYNTAX, Synergy between PCI with TAXUS and Cardiac Surgery. 

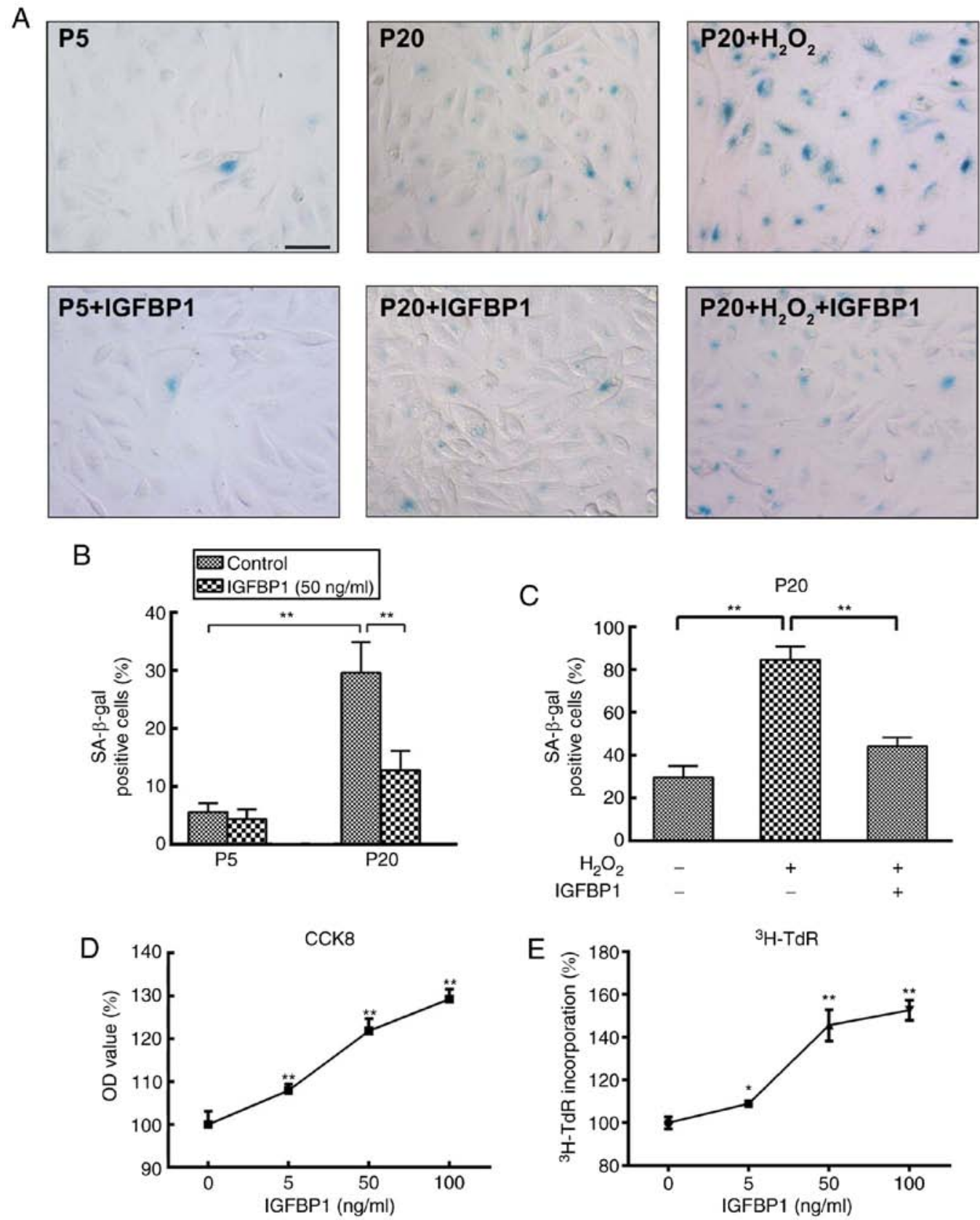

Figure 4. Effects of IGFBP1 on the senescence and proliferation of HCAECs. (A) Representative images of $\beta$-gal staining in HCAECs. P5 and P20 HCAECs were used as young cells and as old cells, respectively. HCAEC were treated with $\mathrm{H}_{2} \mathrm{O}_{2}(0,100 \mu$ mol/l) for $4 \mathrm{~h}$, followed by treatment with IGFBP1 at $50 \mathrm{ng} / \mathrm{ml}$ for $48 \mathrm{~h}$. One of two independent experiments is shown. Scale bar, $50 \mu \mathrm{m}$. (B) Quantification of $\beta$-gal-positive cells in P5 and P20 HCAECs at baseline or

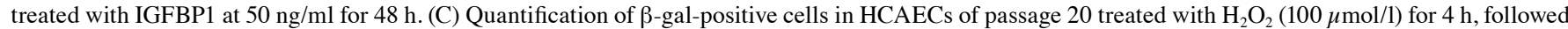
by treatment with IGFBP1 at $50 \mathrm{ng} / \mathrm{ml}$ for $48 \mathrm{~h}$. (D) Quantification of HCAEC proliferation by CCK- 8 assay after treatment with IGFBP1 ( $0,5,50$ and $100 \mathrm{ng} / \mathrm{ml}$ ) for $48 \mathrm{~h}$. (E) Quantification of HCAEC proliferation by ${ }^{3} \mathrm{H}-\mathrm{TdR}$ incorporation after treatment with IGFBP1 (0, 5, 50 and $\left.100 \mathrm{ng} / \mathrm{ml}\right)$ for $48 \mathrm{~h}$. For B, $\mathrm{C}, \mathrm{D}$ and $\mathrm{E}$, one of two independent experiments, each with three biological replicates, is shown. Data are presented as the mean \pm standard deviation, ${ }^{*} \mathrm{P}<0.05$, ${ }^{* *} \mathrm{P}<0.01$ vs. the control or as indicated. IGFBP1, insulin-like growth factor-binding protein 1; CCK-8, Cell Counting Kit-8; HCAECs, human coronary arterial endothelial cells; OD, optical density; P5, passage 5; P20, passage 20; ${ }^{3} \mathrm{H}-\mathrm{TdR}$, tritiated thymidine.

$5.40 \pm 2.07 \%$, respectively; $\mathrm{P}<0.001$ ) (Fig. 4A and B). These findings suggested that P5 cells were in a relatively juvenile status while P20 cells more senescent. Following treatment with $50 \mathrm{ng} / \mathrm{ml}$ IGFBP1 for $48 \mathrm{~h}$, the senescence among P5 cells did not change $(5.60 \pm 1.52 \%$ vs. $4.40 \pm 1.67 \% ; \mathrm{P}=0.269)$. Instead, IGFBP1 significantly decreased the ratio of $\beta$-gal-positive cells among P20 cells $(29.60 \pm 5.27 \%$ vs. $12.80 \pm 3.35 \%$; $\mathrm{P}<0.001)$ (Fig. 4A and B). $\mathrm{H}_{2} \mathrm{O}_{2}$ is a potent senescence inducer. To further understand the role of IGFBP1 in EC senescence and oxidative stimulation in aging, we next examined the protective effects of IGFBP1 against $\mathrm{H}_{2} \mathrm{O}_{2}$-induced senescence in P20 HCAECs. Following incubation with $100 \mu \mathrm{mol} / 1$ of $\mathrm{H}_{2} \mathrm{O}_{2}$ for $4 \mathrm{~h}$, the ratio of $\beta$-gal-positive cells increased significantly; however, the ensuing treatment with IGFBP1 at $50 \mathrm{ng} / \mathrm{ml}$ for $48 \mathrm{~h}$ significantly reversed this increase $(84.60 \pm 6.15 \%$ vs. $44.00 \pm 4.30 \%$; $\mathrm{P}<0.001$ ) in HCAECs (Fig. 4A and C). The senescent cells often exhibit reduced proliferative potential. Consistent with the anti-senescence effect of IGFBP1, we found that IGFBP1 

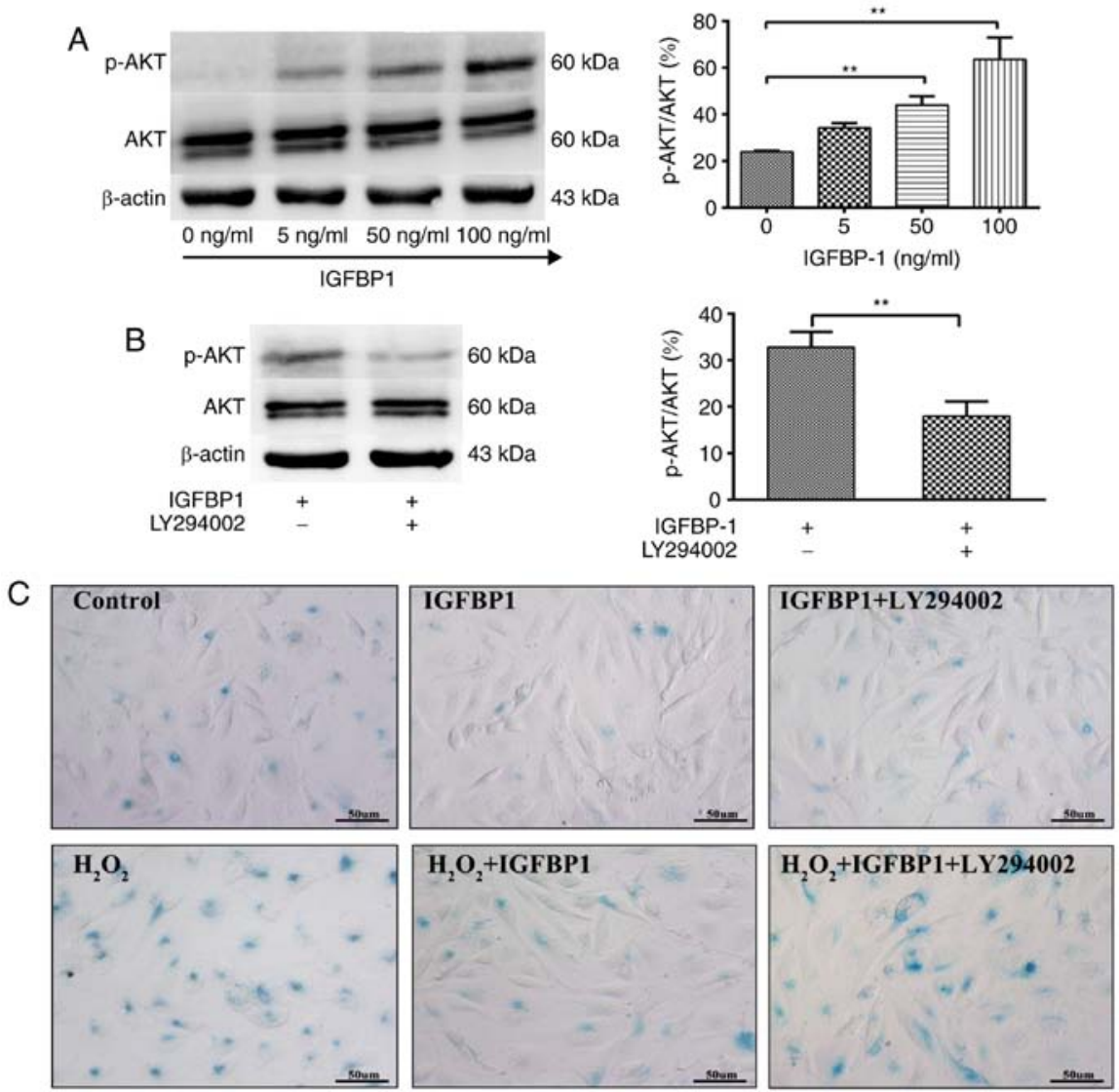

D
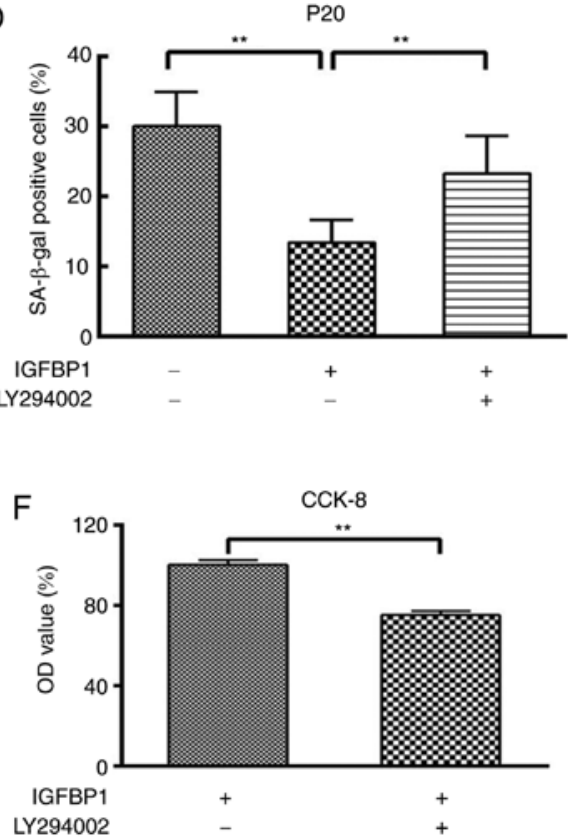

$\mathrm{E}$

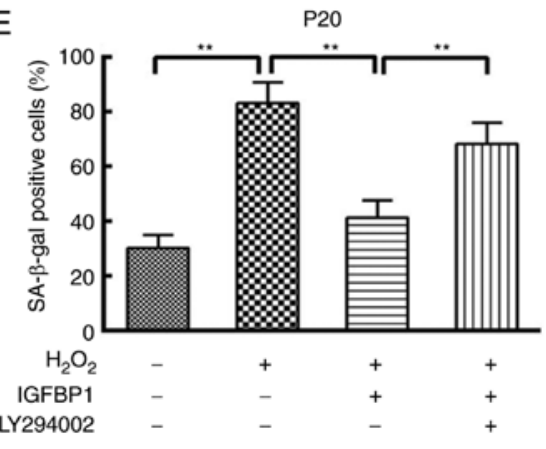

$\mathrm{G}$

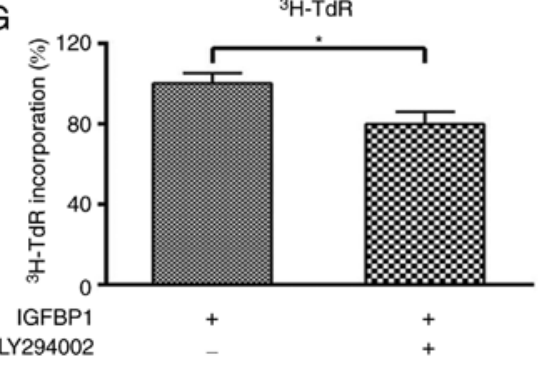

Figure 5. IGFBP1 regulates the senescence and proliferation of HCAECs through AKT signaling. (A) Western blot detection of AKT, p-AKT and $\beta$-actin in HCAEC $48 \mathrm{~h}$ after treatment with IGFBP1 $(0,5,50$ and $100 \mathrm{ng} / \mathrm{ml})$. (B) Western blot detection of AKT, p-AKT and $\beta$-actin in HCAEC treated with IGFBP1 $(50 \mathrm{ng} / \mathrm{ml})$, or IGFBP1 $(50 \mathrm{ng} / \mathrm{ml})$ plus LY294002 $(10 \mu \mathrm{mol} / \mathrm{l})$ for $48 \mathrm{~h}$. For A and B, left, representative images of western blots; right, quantification of western blot band density. p-AKT expression was normalized to both AKT and $\beta$-actin, and the quantification of p-AKT/AKT is shown. (C) Representative images of $\beta$-gal staining of P20 HCAECs. HCAECs were treated with $\mathrm{H}_{2} \mathrm{O}_{2}(100 \mu \mathrm{mol} / \mathrm{l})$ for $4 \mathrm{~h}$, followed by treatment with IGFBP1 (50 ng/ml), or IGFBP1 $(50 \mathrm{ng} / \mathrm{ml})$ plus LY294002 $(10 \mu \mathrm{mol} / \mathrm{l})$ for $48 \mathrm{~h}$. One of two independent experiments is shown. Scale bar, $50 \mu \mathrm{m}$. (D) Quantification of $\beta$-gal-positive cells in P20 HCAECs treated with IGFBP1 $(50 \mathrm{ng} / \mathrm{ml})$, or IGFBP1 $(50 \mathrm{ng} / \mathrm{ml})$ plus LY294002 (10 $\mu \mathrm{mol} / \mathrm{l})$ for $48 \mathrm{~h}$. (E) Quantification of $\beta$-gal-positive cells in P20 HCAECs treated with $\mathrm{H}_{2} \mathrm{O}_{2}(100 \mu \mathrm{mol} / \mathrm{l})$ for $4 \mathrm{~h}$, followed by treatment with IGFBP1 (50 ng/ml), or IGFBP1 (50 ng/ml) plus LY294002 (10 $\left.\mu \mathrm{mol} / \mathrm{l}\right)$ for $48 \mathrm{~h}$. (F) Quantification of proliferation of P20 HCAECs treated with IGFBP1 $(50 \mathrm{ng} / \mathrm{ml})$, or IGFBP1 (50 ng/ml) plus LY294002 (10 $\mu \mathrm{mol} / \mathrm{l})$ for $48 \mathrm{~h} \mathrm{by} \mathrm{a} \mathrm{CCK-8}$ assay. (G) Quantification of proliferation by ${ }^{3} \mathrm{H}-\mathrm{TdR}$ incorporation by P20 HCAECs treated with IGFBP1 (50 ng/ml), or IGFBP1 (50 ng/ml) plus LY294002 $(10 \mu \mathrm{mol} / \mathrm{l})$ for $48 \mathrm{~h}$. For A, B, D, E, F and G, one of two independent experiments, each with three biological replicates, is shown. Data are presented as the mean \pm standard deviation. " $\mathrm{P}<0.05,{ }^{* *} \mathrm{P}<0.01$. AKT, protein kinase B; IGFBP1, insulin-like growth factor-binding protein 1; CCK-8, Cell Counting Kit-8; HCAECs, human coronary arterial endothelial cells; OD, optical density; p, phosphorylated; P5, passage 5; P20, passage 20; ${ }^{3} \mathrm{H}-\mathrm{TdR}$, tritiated thymidine; SA- $\beta$-gal, senescence-associated $\beta$-gal. 
also promoted the proliferation of HCAECs in a concentration-dependent manner, as confirmed in the assays for CCK-8 and ${ }^{3} \mathrm{H}-\mathrm{TdR}$ incorporation (Fig. 4D and E).

Inhibition of Akt signaling reverses the protective effects of IGFBPI on the senescence of HCAECs. Akt signaling regulates the senescence and proliferation of ECs. We further studied the role of Akt signaling in IGFBP1-regulated senescence and the proliferation of HCAECs. We observed that IGFBP1 did not affect the total level of Akt protein in HCAECs. IGFBP1 did not significantly affect the amount of phosphorylated Akt (p-Akt) in the $5 \mathrm{ng} / \mathrm{ml}$ group when compared with the control group $(0 \mathrm{ng} / \mathrm{ml})$. However, p-Akt levels were significantly upregulated in the 50 and $100 \mathrm{ng} / \mathrm{ml}$ groups in a concentration-dependent manner (Fig. 5A). The upregulation of p-Akt by IGFBP1 was blocked by LY294002 (10 $\mu \mathrm{mol} / \mathrm{l})$, a known Akt inhibitor (Fig. 5B). In accordance with this observation, LY294002 intervention also reversed the protective effects of IGFBP1 at baseline and $\mathrm{H}_{2} \mathrm{O}_{2}$-induced conditions, as shown by the number of $\beta$-gal-positive senescent cells (Fig. 5C-E), and CCK-8 viability (Fig. 5F) and ${ }^{3}$ H-TdR incorporation (Fig. 5G) assays of cultured HCAECs.

\section{Discussion}

Recent investigations have revealed a potential link between Notch signaling and aging $(22,23)$. We have previously reported that the expression of Jagged1 decreased in the endothelium of aging mice, and conditional knockdown of Jagged1 expression in the endothelium caused thickening of the vessel wall in young mice, indicating a critical role of Jagged1 in aging-related vascular changes (8). However, it remains largely unknown how Jagged1 mediates these aging-related vascular changes. In the present study, we found that knockdown of Jagged 1 altered the secretory function of HCAEC. By using microarray and protein expression analyses, we identified IGFBP1 as one of the secretory proteins regulated by Jagged1.

IGFBP1 belongs to the IGFBP family, which comprises six structurally similar proteins with high affinity to IGFs, namely IGFBP1 through IGFBP6. IGFBP1 modulates IGF bioactivity through its high-affinity binding and has been implicated in both metabolic homeostasis and cell growth $(14,15)$. Low concentrations of IGFBP1 are associated with insulin resistance and diabetes $(20,21)$. In patients with diabetes, IGFBP1 levels are inversely correlated with cardiovascular disease risk, carotid artery intima thickening and macrovascular diseases (24-27). In other cases, IGFBP1 has been observed to regulate cellular actions independently of IGFs (28). The circulating level of IGFBP1 was previously reported to be associated with age and cardiovascular prognosis (29-31). However, its role in aging CAD patients without diabetes and insulin resistance has not been extensively investigated. Therefore, in the present study, we consecutively enrolled 112 patients who were scheduled for CAG for clinically diagnosed CAD. Consistently with previous reports (30-32), we found that circulating IGFBP1 level was positively correlated with age among the tested patients, and IGFBP1 levels were higher among older patients.

The severity of coronary atherosclerosis is a key factor affecting the outcome of CAD. Currently, the severity and complexity of the obstructive coronary lesions in the clinic are often aggravated by the number of diseased vessels, as well as by various scoring systems (33). SYNTAX score is one of the quantitative tools used to measure the complexity of coronary artery lesions, as well as to guide optimal revascularization therapy in the clinic (34). Of the 112 enrolled subjects, 67 cases $(59.82 \%)$ were confirmed as critical CAD. Among the critical CAD patients, we found that both the incidence of multi-vessel disease and the SYNTAX scores were higher among older patients, indicating that aging is an important factor affecting the development of coronary artery lesions. We also found that the circulating IGFBP1 level was higher in patients with multi-vessel disease compared with those with single-vessel diseases. Moreover, the circulating IGFBP1 level was positively correlated with SYNTAX scores. In particular, IGFBP1 was higher in patients with higher SYNTAX scores among the age-comparable CAD patients. CAG is currently a widely used invasive procedure in the diagnosis of CAD. Screening and identification of CAD patients by non-invasive biomarkers prior to a devastating clinical presentation warrants intensive research $(35,36)$. The data of the present study indicate a potential association between the elevation of serum IGFBP1 levels, and the severity and complexity of coronary atherosclerosis.

To date, the role of IGFBP1 in cardiovascular prognosis remains controversial. Studies by Rajwani et al (37) and Borai et al (38) demonstrated that increased IGFBP1 level protected against atherosclerosis and a low level of IGFBP1 may be a marker of coronary disease risk. Wang et al (39) reported that increased levels of IGFBP1 were detected in human carotid plaques, which may play a role in fibroproliferative processes and contribute to plaque stability. However, in other cases, there were evidence suggesting that an increased level of IGFBP1 is usually associated with the release of inflammatory factors, and is correlated with poor prognosis and high mortality rate $(31,32,34)$. To confirm the role of IGFBP1 in aging-related coronary atherosclerosis, we examined the effects of IGFBP1 on the senescence of HCAEC. IGFBP1 treatment significantly reduced both the passage- and $\mathrm{H}_{2} \mathrm{O}_{2}$-induced senescence of HCAEC. This anti-senescence effect of IGFBP1 was blocked by LY294002 through inhibiting the phosphorylation of Akt in HCAECs. Consistent with its anti-senescence effects, IGFBP1 promoted the proliferation of HCAECs in a concentration-dependent manner. These data suggest that the anti-senescence effects of IGFBP1 were mediated through Akt signaling. Vascular ECs serve a key role in the regulation of vascular remodeling and homeostasis (40). The data of the present study indicate that IGFBP1 plays a crucial protective role in aging-related vascular remodeling. As a natural adaptive measure, the elevation of IGFBP1 may boost EC regeneration in order to counter the development of obstructive coronary artery lesions. However, the final outcome may depend on the interactions between protective and adverse factors.

The major limitation of the present study was the relatively small sample of enrolled subjects. A larger randomized sample across the gender and age range may be more definitive. Long-term follow-up of the changing pattern of IGFBP1, as well as its threshold, in the assessment of coronary artery lesions among individual subjects with different ages warrants further investigation. 
It has been established that aging is an independent risk factor for atherosclerosis $(1,41)$; however, how aging causes vascular lesions remains largely unknown. We observed that, as a Jagged1-regulated secretory protein by EC, the circulating level of IGFBP1 was positively correlated with age and the severity of coronary atherosclerosis. Parallel to these findings, we demonstrated that IGFBP1 protected EC against passageand $\mathrm{H}_{2} \mathrm{O}_{2}$-induced senescence via Akt signaling in cell culture studies. Based on these observations, it appears that IGFBP1 may play a protective role against aging-related vascular disorders, and it may prove to be a promising biomarker and intervention target.

\section{Acknowledgements}

The authors would like to thank Dr Fei Li of the Center for Lung and Vascular Biology, University of Illinois at Chicago for his critical revision of the manuscript.

\section{Funding}

The present study was supported by the National Science Foundation of China (grant nos. 91539104 and 81370404) and the Natural Science Foundation of Shenzhen University General Hospital (grant no. SUGH2018QD048).

\section{Availability of data and materials}

All data generated or analyzed during the present study are included in this published article.

\section{Authors' contributions}

XW and QZ conceived and designed this study and wrote the manuscript. WZ, PJ and JH collected the data of the enrolled patients. WZ, PJ, JH and XW conducted the experiments and analyzed the data. All the authors have read and approved the final version of this manuscript for publication.

\section{Ethics approval and consent to participate}

This observational study was approved by the Institutional Ethics Committee of Xinqiao Hospital (approval no. 2014044), and the investigation conformed to the principles outlined in the Declaration of Helsinki.

\section{Patient consent for publication}

Not applicable.

\section{Competing interests}

The authors declare that they have no competing interests.

\section{References}

1. Mukamal KJ, Kronmal RA, Tracy RP, Cushman M and Siscovick DS: Traditional and novel risk factors in older adults: Cardiovascular risk assessment late in life. Am J Geriatr Cardiol 13: 69-80, 2004.
2. Liu Y, Bloom SI and Donato AJ: The role of senescence, telomere dysfunction and shelterin in vascular aging. Microcirculation 26: e12487, 2019.

3. Ungvari Z, Tarantini S, Kiss T, Wren JD, Giles CB, Griffin CT, Murfee WL, Pacher P and Csiszar A: Endothelial dysfunction and angiogenesis impairment in the ageing vasculature. Nat Rev Cardiol 15: 555-565, 2018.

4. Yildiz O: Vascular smooth muscle and endothelial functions in aging. Ann N Y Acad Sci 1100: 353-360, 2007.

5. Minamino $\mathrm{T}$ and Komuro I: Vascular cell senescence: Contribution to atherosclerosis. Circ Res 100: 15-26, 2007.

6. Yin $\mathrm{H}$ and Pickering JG: Cellular senescence and vascular disease: Novel routes to better understanding and therapy. Can J Cardiol 32: 612-623, 2016.

7. High FA, Lu MM, Pear WS, Loomes KM, Kaestner KH and Epstein JA: Endothelial expression of the Notch ligand Jagged1 is required for vascular smooth muscle development. Proc Natl Acad Sci USA 105: 1955-1959, 2008.

8. Wu X, Zou Y, Zhou Q, Huang L, Gong H, Sun A, Tateno K, Katsube K, Radtke F, Ge J, et al: Role of Jagged1 in arterial lesions after vascular injury. Arterioscler Thromb Vasc Biol 31: 2000-2006, 2011.

9. Wu X, Zhou Q, Huang L, Sun A, Wang K, Zou Y and Ge J: Ageing-exaggerated proliferation of vascular smooth muscle cells is related to attenuation of Jagged 1 expression in endothelial cells. Cardiovasc Res 77: 800-808, 2008.

10. Tetzlaff $\mathrm{F}$ and Fischer A: Control of blood vessel formation by Notch signaling. Adv Exp Med Biol 1066: 319-338, 2018.

11. Gridley T: Notch signaling in vascular development and physiology. Development 134: 2709-2718, 2007.

12. Lindner V, Booth C, Prudovsky I, Small D, Maciag T and Liaw L: Members of the Jagged/Notch gene families are expressed in injured arteries and regulate cell phenotype via alterations in cell matrix and cell-cell interaction. Am J Pathol 159: 875-883, 2001.

13. Rodríguez-Flores M, Rodríguez-Saldaña J, Cantú-Brito C, Aguirre-García J and Alejandro GG: Prevalence and severity of atherosclerosis in different arterial territories and its relation with obesity. Cardiovasc Pathol 22: 332-338, 2013.

14. van der Kaay D, Deal C, de Kort S, Willemsen R, Leunissen R, Ester W, Paquette J, van Doorn J and Hokken-Koelega A: Insulin-like growth factor-binding protein-1: Serum levels, promoter polymorphism, and associations with components of the metabolic syndrome in short subjects born small for gestational age. J Clin Endocrinol Metab 94: 1386-1392, 2009.

15. Hu D, Pawlikowska L, Kanaya A, Hsueh WC, Colbert L, Newman AB, Satterfield S, Rosen C, Cummings SR, Harris TB, et al: Serum insulin-like growth factor-1 binding proteins 1 and 2 and mortality in older adults: The health, aging, and body composition study. J Am Geriatr Soc 57: 1213-1218, 2009.

16. Yu YL, Chou RH, Shyu WC, Hsieh SC, Wu CS, Chiang SY, Chang WJ, Chen JN, Tseng YJ, Lin YH, et al: Smurf2-mediated degradation of EZH2 enhances neuron differentiation and improves functional recovery after ischaemic stroke. EMBO Mol Med 5: 531-547, 2013.

17. Lee MY, Wang Y and Vanhoutte PM: Senescence of cultured porcine coronary arterial endothelial cells is associated with accelerated oxidative stress and activation of NFkB. J Vasc Res 47: 287-298, 2010

18. Shi Q, Aida K, Vandeberg JL and Wang XL: Passage-dependent changes in baboon endothelial cells-relevance to in vitro aging. DNA Cell Biol 23: 502-509, 2004

19. Livak KJ and Schmittgen TD: Analysis of relative gene expression data using real-time quantitative PCR and the 2(-Delta Delta C(T)) method. Methods 25: 402-408, 2001.

20. Leinonen ES, Salonen JT, Salonen RM, Koistinen RA, Leinonen PJ, Sarna SS and Taskinen MR: Reduced IGFBP-1 is associated with thickening of the carotid wall in type 2 diabetes. Diabetes Care 25: 1807-1812, 2002.

21. Heald AH, Siddals KW, Fraser W, Taylor W, Kaushal K, Morris J, Young RJ, White A and Gibson JM: Low circulating levels of insulin-like growth factor binding protein-1 (IGFBP-1) are closely associated with the presence of macrovascular disease and hypertension in type 2 diabetes. Diabetes 51: 2629-2636, 2002.

22. Quillien A, Moore JC, Shin M, Siekmann AF, Smith T, Pan L, Moens CB, Parsons MJ and Lawson ND: Distinct Notch signaling outputs pattern the developing arterial system. Development 141: 1544-1552, 2014 
23. Balistreri CR, Madonna R, Melino G and Caruso C: The emerging role of Notch pathway in ageing: Focus on the related mechanisms in age-related diseases. Ageing Res Rev 29: 50-65, 2016.

24. Venkatesh D, Fredette N, Rostama B, Tang Y, Vary CP, Liaw L and Urs S: RhoA-mediated signaling in Notch-induced senescence-like growth arrest and endothelial barrier dysfunction. Arterioscler Thromb Vasc Biol 31: 876-882, 2011.

25. Sandhu MS, Heald AH, Gibson JM, Cruickshank JK, Dunger DB and Wareham NJ: Circulating concentrations of insulin-like growth factor-I and development of glucose intolerance: A prospective observational study. Lancet 359: 1740-1745, 2002.

26. Heald AH, Cruickshank JK, Riste LK, Cade JE, Anderson S, Greenhalgh A, Sampayo J, Taylor W, Fraser W, White A and Gibson JM: Close relation of fasting insulin-like growth factor binding protein-1 (IGFBP-1) with glucose tolerance and cardiovascular risk in two populations. Diabetologia 44: 333-339, 2001

27. Lewitt MS, Hilding A, Ostenson CG, Efendic S, Brismar K and Hall K: Insulin-like growth factor-binding protein-1 in the prediction and development of type 2 diabetes in middle-aged Swedish men. Diabetologia 51: 1135-1145, 2008.

28. Wheatcroft SB and Kearney MT: IGF-dependent and IGF-independent actions of IGF-binding protein-1 and -2: Implications for metabolic homeostasis. Trends Endocrinol Metab 20: 153-162, 2009.

29. Janssen JA, Stolk RP, Pols HA, Grobbee DE and Lamberts SW: Serum total IGF-I, free IGF-I, and IGFB-1 levels in an elderly population: Relation to cardiovascular risk factors and disease. Arterioscler Thromb Vasc Biol 18: 277-282, 1998.

30. Nolte AA, Movin M, Lundin H and Salminen H: IGFBP-1 predicts all-cause mortality in elderly women independently of IGF-I. Growth Horm IGF Res 25: 281-285, 2015.

31. Chisalita SI, Dahlström U, Arnqvist HJ and Alehagen U: Proinsulin and IGFBP-1 predicts mortality in an elderly population. Int J Cardiol 174: 260-267, 2014

32. Rutkute $\mathrm{K}$ and Nikolova-Karakashian MN: Regulation of insulin-like growth factor binding protein-1 expression during aging. Biochem Biophys Res Commun 361: 263-269, 2007.

33. Kalkan K, Hamur H, Yildirim E, Ipek E, Ermis E, Ozturk M, Karal H, Korkmaz AF, Bayantemur M and Demirelli S: The comparison of angiographic scoring systems with the predictors of atherosclerosis. Angiology 69: 158-163, 2018.
34. Wykrzykowska JJ, Garg S, Girasis C, de Vries T, Morel MA, van Es GA, Buszman P, Linke A, Ischinger T, Klauss V, et al: Value of the SYNTAX score for risk assessment in the all-comers population of the randomized multicenter LEADERS (Limus Eluted from A Durable versus ERodable Stent coating) trial. J Am Coll Cardiol 56: 272-277, 2010.

35. Vogel RA: Biomarkers of high-grade coronary stenosis: Searching for seventies. J Am Coll Cardiol 69: 1157-1159, 2017.

36. Ibrahim NE, Januzzi JL Jr, Magaret CA, Gaggin HK, Rhyne RF, Gandhi PU, Kelly N, Simon ML, Motiwala SR, Belcher AM and van Kimmenade RRJ: A clinical and biomarker scoring system to predict the presence of obstructive coronary artery disease. J Am Coll Cardiol 69: 1147-1156, 2017.

37. Rajwani A, Ezzat V, Smith J, Yuldasheva NY, Duncan ER, Gage M, Cubbon RM, Kahn MB, Imrie H, Abbas A, et al: Increasing circulating IGFBP1 levels improves insulin sensitivity, promotes nitric oxide production, lowers blood pressure, and protects against atherosclerosis. Diabetes 61: 915-924, 2012.

38. Borai A, Livingstone C, Ghayour-Mobarhan M, Abuosa A, Shafi S, Mehta S, Heidari A, Emadzadeh A, Wark G and Ferns G: Serum insulin-like growth factor binding protein-1 (IGFBP-1) phosphorylation status in subjects with and without ischaemic heart disease. Atherosclerosis 208: 593-598, 2010.

39. Wang J, Razuvaev A, Folkersen L, Hedin E, Roy J, Brismar K and Hedin U: The expression of IGFs and IGF binding proteins in human carotid atherosclerosis, and the possible role of IGF binding protein-1 in the regulation of smooth muscle cell proliferation. Atherosclerosis 220: 102-109, 2012.

40. Cahill PA and Redmond EM: Vascular endothelium-Gatekeeper of vessel health. Atherosclerosis 248: 97-109, 2016.

41. Head T, Daunert S and Goldschmidt-Clermont PJ: The aging risk and atherosclerosis: A fresh look at arterial homeostasis. Front Genet 8: 216, 2017.

This work is licensed under a Creative Commons Attribution-NonCommercial-NoDerivatives 4.0 International (CC BY-NC-ND 4.0) License. 